\title{
Intravenous Antibiotic Durations for Common Bacterial Infections in Children: When is Enough Enough?
}

\author{
Alan R. Schroeder, MD*, Shawn L. Ralston, MD²
}

${ }^{1}$ Department of Pediatrics, Santa Clara Valley Medical Center, San Jose, California; ${ }^{2}$ Department of Pediatrics, Geisel School of Medicine at Dartmouth, Hanover, New Hampshire.

Durations of intravenous antibiotic therapy for bacterial infections in hospitalized children sometimes extend well beyond clinical recovery and are often the primary determinants of length of stay. These durations, however, are not always based on solid evidence. Moreover, fixed durations are invariant to important individual factors. We review guidelines and the available evidence for durations of intravenous antibiotic therapy for meningitis, bacteremia, urinary tract infection, and osteomyelitis, conditions where intravenous antibiotics often extend beyond resolution of clinical symptoms. We propose a framework for the duration of therapy that is intended to serve as a guide when standards of care are either nonexistent, dated, conflicting, or contrary to evidence from published studies. This framework incorporates patient-centered factors such as severity of infection, response to therapy, ease of intravenous access, harms and costs of ongoing intravenous treatment, and family preferences. Journal of Hospital Medicine 2014;9:604-609. (C) 2014 Society of Hospital Medicine
Rationally defining the appropriate duration of intravenous (IV) antibiotics for children with bacterial infections is challenging. For example, how long should a 2-week-old infant with a urinary tract infection (UTI) caused by Escherichia coli (E coli) be treated intravenously if the infant has responded to treatment and is back to baseline within 1 to 2 days? What if the blood culture was also positive for E coli? What are the risks and benefits of continuing IV antibiotics?

Such questions are common for pediatric hospitalists. Bacterial infections remain a relatively frequent cause of pediatric hospitalization, especially in neonates where 5 of the top 10 causes of hospitalizations are related to bacterial infections. ${ }^{1}$ For some conditions, children remain hospitalized after clinical improvement simply for ongoing provision of IV antibiotics. Alternatively, some children are discharged home with a peripherally inserted central catheter (PICC) to complete an IV course.

The decision regarding the duration of IV antibiotics varies according to the condition for which the antibiotic is prescribed and often by practitioner or hospital. Many recommendations are numerically based (eg, 10 days for group B Streptococcus [GBS] bacteremia, 21 days for $E$ coli meningitis), without taking into account patient-level factors such as initial

*Address for correspondence and reprint requests: Alan Schroeder, MD, Department of Pediatrics, Santa Clara Valley Medical Center, 751 S Bascom Ave., San Jose, CA 95218; Telephone: 408-885-3612; Fax: 408885-5263; E-mail: alan.schroeder@hhs.sccgov.org

Additional Supporting Information may be found in the online version of this article.

Received: March 13, 2014; Revised: June 23, 2014; Accepted: July 7 , 2014

2014 Society of Hospital Medicine DOI 10.1002/jhm.2239

Published online in Wiley Online Library (Wileyonlinelibrary.com). severity or response to therapy. These concrete recommendations may in fact be preferred by some practitioners, as suggested by a former chairman of the Committee on Infectious Disease for the American Academy of Pediatrics (AAP): "The Red Book is designed for people who make decisions. It cannot waffle on an issue. It has to make a positive recommendation even if the data are incomplete." ${ }^{2}$ A potential downside of this mentality, however, is that some practitioners may then feel obligated to follow these recommendations despite the lack of supportive evidence.

\section{EXTENDING IV ANTIBIOTICS BEYOND CLINICAL RECOVERY}

What is the rationale for continuing IV antibiotics in infants whose symptoms have completely resolved? Several factors likely drive these decisions: prevention of recurrences, concerns about bioavailability of enteral antibiotics and patient compliance, adherence to expert recommendations/guidelines, and perhaps a general sense that more is better-that serious infections and/or their sequelae require more aggressive treatments.

Recurrence of a potentially life-threatening infection is an understandable concern. Even when symptoms have resolved and there is documented clearance of the infection, such clearance does not necessarily signify that the body has rid itself of the pathogen completely. Some infections are deep seated and may warrant continuing treatment despite apparent recovery. To some, the risks of prolonging IV therapy may seem inconsequential when juxtaposed to a potentially devastating recurrence. However, in many conditions, recurrences may be related to host issues or ongoing exposures rather than inadequate treatment of the original infection. Recurrent UTIs, for example, are 
TABLE 1. Recommended Duration of Intravenous Antibiotics for Meningitis in Children

\begin{tabular}{lccc}
\hline Pathogen & IDSA & NICE & $\begin{array}{c}\text { Minimum Range } \\
\text { Achieving Equivalent } \\
\text { Outcomes in Recent } \\
\text { Randomized Trials }\end{array}$ \\
\hline Group B Streptococcus & $14-21$ days & 14 days & None available \\
Neisseria meningititis & 7 days & 7 days & $1-5$ days ${ }^{12-14}$ \\
Haemophilus influenzae type b & 7 days & 10 days & $4-5$ days ${ }^{12,13}$ \\
Streptococcus pneumoniae & $10-14$ days & 14 days & $4-5$ days \\
\hline
\end{tabular}

NOTE: Abbreviations: IDSA, Infectious Disease Society of America; NICE, National Institute for Clinical Excellence.

more likely in infants with urologic abnormalities, ${ }^{3}$ and recurrent GBS bacteremia has been associated with GBS colonization of maternal breast milk and/or maternal mastitis. ${ }^{4-7}$ Although it is tempting to extend IV courses to prevent recurrences, it is not clear that the benefits of such an approach outweigh the risks.

Concerns over enteral absorption and bioavailability are also understandable, especially in young infants. The superior efficacy of IV over oral antibiotics in general is well accepted for many pediatric conditions, and in some cases (eg, septic shock) it would be unethical to perform a head-to-head trial. However, the lack of any published trials (to our knowledge) in pediatrics confirming the superiority of IV antibiotics suggests that oral antibiotic absorption is sufficient for many infections. Even in neonates, several studies have demonstrated that therapeutic serum levels are easily reached with oral dosing of amoxicillin in term and preterm neonates. 8,9

For the remainder of this review, the published recommendations and available evidence behind the duration of IV therapy are summarized for 4 bacterial infections in children in which IV antibiotic therapy often continues after clinical recovery: meningitis, bacteremia, UTI, and acute osteomyelitis. We conclude by proposing additional considerations for IV antibiotic durations, especially in situations where guidelines and/or evidence are either nonexistent, dated, conflicting, or contrary to evidence from published studies.

\section{BACTERIAL MENINGITIS}

The Infectious Disease Society of America and the British National Institute for Clinical Evidence have both published guidelines with pediatric recommendations for duration of therapy in bacterial meningitis, ${ }^{10,11}$ though the recommendations differ somewhat for 3 of the 4 most common pathogens, and are not always concordant with evidence from randomized controlled trials (Table 1). ${ }^{12-14}$

A recent meta-analysis on duration of therapy in meningitis included 5 open-label trials of ceftriaxone for bacterial meningitis in children. ${ }^{12}$ These trials included the 3 most common pathogens and were categorized as short-course (4-7 days, $\mathrm{n}=196$ patients) and long-course (7-14 days, $\mathrm{n}=187$ patients) therapy. There was no significant difference in clinical success or long-term neurological complications between groups. Subsequently, a multicountry trial enrolled over 1000 children 2 months to 12 years of age with meningitis caused by Haemophilus influenzae type b, Streptococcus pneumonia, or Neisseria meningititis who were stable after 5 days of IV ceftriaxone therapy and randomized them to receive placebo or an additional 5 days of ceftriaxone. ${ }^{13}$ Patients with persistence of seizures, bacteremia, abscess or distant infections, or who were judged to be deteriorating or still severely ill at the 5-day point were excluded $(\sim 4.7 \%$ of the children who were recruited on day 0). There were no significant differences in bacteriologic failures, clinical failures, or clinical sequelae in survivors. The authors concluded that ceftriaxone can be discontinued in children with bacterial meningitis who are clinically stable after 5 days of IV therapy. Further trials in developed countries are needed.

\section{BACTEREMIA}

Because of routine vaccination against $H$ influenzae type $\mathrm{b}$ and $S$ pneumoniae, bacteremia beyond the first few months of life in otherwise healthy children is now rare. $^{15}$ Even in infants too young to benefit directly from vaccination, the epidemiology of bacteremia has changed considerably over the last few decades, with E coli and GBS constituting the majority $(65 \%-77 \%)$ of cases. ${ }^{16,17}$ We will limit this review on bacteremia to these 2 organisms in young infants.

Most cases of E coli bacteremia are associated with UTI $(91 \%-98 \%),{ }^{16,17}$ and most bacteremic UTIs $(88 \%-92 \%)$ are caused by $E$ coli. ${ }^{18-21}$ There are no official recommendations for the duration of treatment of bacteremic UTI, and only a limited amount of evidence can be gleaned from existing studies. In a trial of oral cefixime for infants aged 1 to 24 months with UTI, all 13 infants with bacteremia fared well whether they received oral cefixime only or IV cefotaxime for 3 days followed by oral cefixime. ${ }^{18}$ In a study on length of IV antibiotic therapy in over 12,000 infants $<6$ months old with UTI, the presence of bacteremia predicted longer IV treatment length (bacteremia was present in $0.5 \%$ of the short IV group vs $0.8 \%$ of the long IV group, $P=0.02$ ) but did not predict treatment failure, defined as readmission within 30 days. ${ }^{3}$ In a multicenter investigation of 229 infants $<3$ months old with bacteremic UTI, the duration of parenteral antibiotics was extremely variable (range, 1-17 days) and was not associated with treatment failure, defined as recurrent UTI caused by the same organism within 30 days (mean duration 7.8 days in the treatment-failure group vs 7.7 days in the no-failure group, $P=0.99) .{ }^{21}$ In summary, there is no 
evidence to support a prolonged course (ie, $>3-5$ days) of IV antibiotics for bacteremic UTI.

For bacteremia caused by GBS, although the Red Book Committee on Infectious Disease recommends 10 days of IV antibiotics, ${ }^{22}$ to our knowledge there are no experimental or observational investigations to support this recommendation. Although available studies suggest that IV courses of at least 10 days are generally provided, ${ }^{7,23}$ no studies have compared outcomes of infants treated with short versus long courses. However, in a study that included 29 fullterm neonates with GBS bacteremia, all 29 had responded initially to 48 hours of intravenous antibiotics (defined as being "asymptomatic" and fed enterally), and were then treated successfully with highdose oral amoxicillin for the remainder of the course, with no recurrences. ${ }^{8}$ Although recurrences are estimated to occur in $0.5 \%$ to $3 \%$ of babies treated for GBS infections, many recurrences are associated with exposure factors such as GBS colonization of the breast milk. ${ }^{4-7}$ In summary, although 10 or more days of IV antibiotic therapy remains a common published recommendation, there is no supportive evidence. More research is needed to assess whether shorter IV courses are safe.

\section{UTI}

Most UTIs can be treated with oral antibiotics. ${ }^{24}$ In its practice parameter on febrile UTIs in infants 2 months to 2 years of age, the AAP recommends oral antibiotics for well-appearing children. ${ }^{25}$ This recommendation is supported by a recent Cochrane review on the topic, ${ }^{26}$ and at least 3 additional trials that have demonstrated that long IV courses do not yield better outcomes than shorter IV courses or oral only courses. $^{27-29}$

However, all of these trials exclude infants $<1$ month old, and there are no published recommendations for the $<2$-month-old age group. The study by Brady et al. on $>12,000$ infants $<6$ months old with UTI demonstrated no significant differences in UTI readmission rates between infants who were given $\geq 4$ days of IV antibiotics versus those who were given $<4$ days. ${ }^{3}$ There were 3,383 infants $<30$ days old in this study, and about one-third of these babies received a short IV course. Failure rates were nearly identical in each group $(2.3 \%$ in short course vs $2.4 \%$ in long course) even after risk adjustment (personal communication with Patrick Brady, MD, on February 7, 2014). Magin et al. describe 172 neonates (median age 19 days) with UTI who were treated intravenously for a median duration of 4 days (interquartile range, 3-6 days) and did not experience treatment failures or relapses. ${ }^{30}$

In summary, most cases of UTI can be managed with oral antibiotics. Uncertainty remains over the optimal approach for infants $<1$ to 2 months old, an age range not considered in current published guide- lines. Current evidence suggests that IV treatment for 3 to 4 days followed by oral therapy may be sufficient treatment in this age group.

\section{ACUTE OSTEOMYELITIS}

Given the excellent blood supply to rapidly growing tissues in children, shorter durations of IV therapy have been studied with increasing frequency. A 2002 systematic review included 12 prospective cohort studies with at least 6 months of follow-up. ${ }^{31}$ Studies were stratified into $\leq 7$ days or $>7$ days IV therapy, and there were no differences in cure rates. Subsequently, a large Finnish trial reported on 131 children who received an initial short IV course (2-4 days) followed by 20 versus 30 total days of therapy with very low treatment failure rates. ${ }^{32}$

The largest study from the United States to date analyzed nearly 2000 cases of osteomyelitis from 29 hospitals. ${ }^{33}$ This study defined a prolonged IV course by placement of a central venous catheter. The rates of prolonged IV therapy varied significantly across hospitals, ranging from $10 \%$ to $95 \%$ of patients, without detectable differences in outcomes. Furthermore, the readmission rate for catheter related complications $(3 \%)$ was nearly as high as the overall treatment failure rate $(4 \%-5 \%)$. Recently, Arnold et al. reported 8 years' experience with a management algorithm to guide the transition to oral antibiotics in pediatric osteoarticular infections in a patient specific manner. ${ }^{34}$ This study included 194 patients (154 uncomplicated and 40 complicated cases), all with culture-proven disease. Transition to oral antibiotics occurred based on resolution of fever and pain, improved function of the affected region, and a Creactive protein level of $<3 \mathrm{mg} / \mathrm{dL}$, and occurred at an average of 10 days into the treatment course. These authors also provided extensive information about complications to demonstrate that the proposed strategy can be used with a wide range of patients and pathogens. There was a single microbiologic treatment failure after oral step-down therapy in a complicated osteoarticular infection, with a retained bony fragment. This study represents a successful example of a patient-centered approach to IV antibiotic duration.

\section{A PATIENT-CENTERED APPROACH}

Returning to the example above of the 2-week-old with UTI (with or without bacteremia), there are no published guidelines and only limited available evidence to help guide the duration of IV antibiotics in this case. When standards of care (eg, from published guidelines, review articles, textbooks, or local expert guidance) are nonexistent, conflicting, dated, or contrary to existing evidence, patient-level factors can be incorporated into the decision-making process (Table 2 ). In these cases, tailoring the IV antibiotic course to the individual's response (referred to in 1 review as 
TABLE 2. Additional Considerations for the Duration of Intravenous Antibiotics When Guidelines Are Conflicting, Absent, Dated, or Contrary to Existing Evidence

\begin{tabular}{lc}
\hline Consideration & Description \\
\hline Severity of initial infection & If concern of recurrence is the justification for a \\
& longer IV course, then a more prolonged \\
course might be considered for a more severe & initial presentation (eg, septic shock, multisys- \\
tem organ failure, intensive care unit & admission). \\
Continued IV antibiotics might be warranted in \\
patients who are still symptomatic (eg, fever, \\
vomiting). Inflammatory markers have been \\
used to guide therapy in osteomyelitis. ${ }^{34}$ \\
If a child does not tolerate oral antibitics or there \\
are concerns about family adherence, a longer \\
IV course may be considered. \\
Shared decision making can be employed, espe- \\
cially when there is no clear evidence support- \\
ing a specific duration. \\
Family preferences
\end{tabular}

NOTE: Abbreviations: IV, intravenous.

"the ultimate bioassay of the therapy"2), while also weighing risks and benefits of ongoing therapy, is a logical approach.

\section{SEVERITY OF INITIAL INFECTION AND RESPONSE TO THERAPY}

The severity of the initial infection, whether in terms of presentation or clinical recovery, can factor into the duration of therapy. Provision of a longer IV course to prevent (albeit theoretically) a recurrence makes more logical sense in an infant with GBS bacteremia who was ill enough to warrant intensive care unit admission than in an infant whose only symptom was a fever. Similarly, most practitioners would be reluctant to stop IV antibiotics and discharge a patient with a bacterial infection who is persistently febrile or vomiting. Although the use of inflammatory markers and other clinical symptoms to guide therapy has been limited to osteomyelitis, this approach might be useful and should be studied in other conditions.

\section{SHARED DECISION MAKING}

Shared decision making can also be employed. Parents of sick, hospitalized children generally prefer to be involved in the decision-making process. ${ }^{35}$ For a parent who has concerns about their child's well-being in the hospital, or has multiple other children at home, competing career obligations, and/or limited family support, the burden of ongoing hospitalization can be significant, and should be factored into decision making. Involving parents in medical decisions may lead to a reduction in utilization for some conditions. ${ }^{36}$

\section{ASSESSMENT OF RISKS/COSTS}

The risks and costs of pediatric hospitalization and prolonged IV antibiotics are well described in the literature and are summarized in Table 3. Although the benefits of prolonging IV antibiotics in a child who has recovered from an acute bacterial infection are largely theoretical, many of the risks are concrete and quantifiable. For example, a young infant being treated for a bacteremic UTI may run out of potential IV sites and need a PICC line to continue IV therapy, which according to a recent review of 2574 PICC lines has a $21 \%$ complication rate. This rate is even higher in children for whom the PICC line indication was provision of antibiotics $(27 \%)$ and for infants $<1$ year of age $(44 \%) .{ }^{37}$ Moreover, this procedure often requires sedation or anesthesia for placement, which has both known and unknown risks, including concerns about subsequent adverse effects on development in young children. ${ }^{38}$ Nosocomial exposure to

TABLE 3. Harms Associated With Intravenous Antibiotic Therapy

\begin{tabular}{|c|c|}
\hline Harm of Intravenous Antibiotic Therapy & Description or Example \\
\hline Complications from peripheral IV catheter & $\begin{array}{l}\text { Leading source of pain and distress for hospitalized children. }{ }^{44} \\
\text { Serious complications can occur following IV infiltrates. }\end{array}$ \\
\hline Complications from PICC line & $\begin{array}{l}\text { Approximately } 20 \% \text { overall complication rate ( } 44 \% \text { in infants }<1 \text { year old). }{ }^{37} \\
\text { Complications led to rehospitalization of } 3 \% \text { of children being treated with prolonged antibiotics for } \\
\text { osteomyelitis. } \\
\text { When thrombosis occurs (up to } 9 \% \text { risk in neonates }{ }^{46} \text { ), } 3 \text { months of anticoagulation is recommended. }{ }^{47} \\
\text { Complications may arise from sedation/anesthesia necessary to place catheter. Anesthesia has been } \\
\text { associated with adverse behavioral or developmental outcomes in children }<4 \text { years of age. }{ }^{38}\end{array}$ \\
\hline Risk of nosocomial infection while hospitalized & $\begin{array}{l}\text { An estimated } 6 \% \text { of hospital RSV infections are nosocomial, which are associated with a more prolonged LOS } \\
\text { than hospitalizations for community-acquired RSV. }\end{array}$ \\
\hline Medication error & $\begin{array}{l}\text { In } 1 \text { investigation, serious medication errors occurred in } 22 \text { per 1,000 patient-days in a large children's } \\
\text { hospital. }^{48}\end{array}$ \\
\hline Emotional and financial burdens & Hospitalization can pose a significant strain on the child, parents, and siblings. \\
\hline Financial costs to healthcare system & In 2003, infection-related hospitalizations in infants had an average cost of $\$ 4,000$ (average LOS 3.5 days). ${ }^{1}$ \\
\hline Harms associated with prolonged courses of antibiotics in general (IV or P0) & Antibiotic resistance, diarrhea (including Clostridium difficile), allergic reactions, increased costs. ${ }^{49}$ \\
\hline
\end{tabular}


seasonal viruses poses an additional risk to hospitalized children. ${ }^{39}$

These additional considerations for the duration of IV antibiotics are not evidence based and should not be used to justify an IV duration that differs dramatically from an accepted standard of care. These are merely considerations that incorporate clinical judgment and a comprehensive analysis of risks and benefits in situations where the available evidence is suboptimal. This approach can be adopted both as a framework for future research and directly in clinical practice.

\section{CONCLUSION}

In an era of increasing focus on overtreatment/ waste, ${ }^{40}$ patient safety, ${ }^{41}$ and patient-centered care, ${ }^{42}$ the duration of IV antibiotics for common bacterial infections is a prime target for improving pediatric healthcare value. As emphasized by Michael Porter recently in The New England Journal of Medicine, "value should always be defined around the customer." ${ }^{43}$ A high-value approach to IV antibiotic duration incorporates a rigorous assessment of risks and benefits that focuses on best evidence and patient-level factors.

In discussing published guidelines in a review on bacterial meningitis therapy, Michael Radetsky noted that " $[R]$ ecommended criteria, even if provisional, may inadvertently become invested with an independent power to force submission and prohibit deviation. The danger is that sensitivity to individual responsiveness and variability will be lost." ${ }^{2}$ Guidelines are useful tools in pediatrics and should continue to be used to direct IV antibiotic durations for bacterial infections in children. However, the emphasis on fixed durations of IV antibiotics might not always serve the best interest of the patient. When guidelines are lacking or contradictory, patient factors should also be considered.

\section{Acknowledgements}

The authors thank Ellen R. Wald, MD, and Kenneth B. Roberts, MD, for their thoughtful and valuable additions to this review.

Disclosure: Nothing to report.

\section{References}

1. Yorita KL, Holman RC, Sejvar JJ, Steiner CA, Schonberger LB. Infectious disease hospitalizations among infants in the United States. Pediatrics. 2008;121(2):244-252.

2. Radetsky M. Duration of treatment in bacterial meningitis: a historical inquiry. Pediatr Infect Dis J. 1990;9(1):2-9.

3. Brady PW, Conway PH, Goudie A. Length of intravenous antibiotic therapy and treatment failure in infants with urinary tract infections. Pediatrics. 2010;126(2):196-203.

4. Filleron A, Lombard F, Jacquot A, et al. Group B streptococci in milk and late neonatal infections: an analysis of cases in the literature. Arch Dis Child Fetal Neonatal Ed. 2014;99(1):F41-F47.

5. Jawa G, Hussain Z, da Silva O. Recurrent late-onset group B Streptococcus sepsis in a preterm infant acquired by expressed breastmilk transmission: a case report. Breastfeed Med. 2013;8(1):134-136.

6. Kotiw M, Zhang GW, Daggard G, Reiss-Levy E, Tapsall JW, Numa A. Late-onset and recurrent neonatal Group B streptococcal disease associated with breast-milk transmission. Pediatr Dev Pathol. 2003; 6(3):251-256.
7. Moylett EH, Fernandez M, Rench MA, Hickman ME, Baker CJ. A 5year review of recurrent group B streptococcal disease: lessons from twin infants. Clin Infect Dis. 2000;30(2):282-287.

8. Gras-Le Guen C, Boscher C, Godon N, et al. Therapeutic amoxicillin levels achieved with oral administration in term neonates. Eur J Clin Pharmacol. 2007;63(7):657-662.

9. Pullen J, Stolk LM, Nieman FH, Degraeuwe PL, van Tiel FH, Zimmermann LJ. Population pharmacokinetics and dosing of amoxicillin in (pre)term neonates. Ther Drug Monit. 2006;28(2):226-231.

10. Tunkel AR, Hartman BJ, Kaplan SL, et al. Practice guidelines for the management of bacterial meningitis. Clin Infect Dis. 2004;39(9): $1267-1284$.

11. Visintin C, Mugglestone MA, Fields EJ, Jacklin P, Murphy MS, Pollard AJ. Management of bacterial meningitis and meningococcal septicaemia in children and young people: summary of NICE guidance. BMJ. 2010;340:c3209.

12. Karageorgopoulos DE, Valkimadi PE, Kapaskelis A, Rafailidis PI, Falagas ME. Short versus long duration of antibiotic therapy for bacterial meningitis: a meta-analysis of randomised controlled trials in children. Arch Dis Child. 2009;94(8):607-614.

13. Molyneux E, Nizami SQ, Saha S, et al. 5 versus 10 days of treatment with ceftriaxone for bacterial meningitis in children: a double-blind randomised equivalence study. Lancet. 2011;377(9780):1837-1845.

14. Nathan N, Borel T, Djibo A, et al. Ceftriaxone as effective as longacting chloramphenicol in short-course treatment of meningococcal meningitis during epidemics: a randomised non-inferiority study. Lancet. 2005;366(9482):308-313.

15. Herz AM, Greenhow TL, Alcantara J, et al. Changing epidemiology of outpatient bacteremia in 3- to 36-month-old children after the introduction of the heptavalent-conjugated pneumococcal vaccine. Pediatr Infect Dis J. 2006;25(4):293-300.

16. Biondi E, Evans R, Mischler M, et al. Epidemiology of bacteremia in febrile infants in the United States. Pediatrics. 2013;132(6):990-996.

17. Greenhow TL, Hung YY, Herz AM. Changing epidemiology of bacteremia in infants aged 1 week to 3 months. Pediatrics. 2012;129(3): e590-e596.

18. Hoberman A, Wald ER, Hickey RW, et al. Oral versus initial intravenous therapy for urinary tract infections in young febrile children. Pediatrics. 1999;104(1 pt 1):79-86.

19. Honkinen O, Jahnukainen T, Mertsola J, Eskola J, Ruuskanen O. Bacteremic urinary tract infection in children. Pediatr Infect Dis J. 2000;19(7):630-634.

20. Newman TB, Bernzweig JA, Takayama JI, Finch SA, Wasserman RC, Pantell RH. Urine testing and urinary tract infections in febrile infants seen in office settings: the Pediatric Research in Office Settings' Febrile Infant Study. Arch Pediatr Adolesc Med. 2002;156(1):44-54.

21. Schroeder AR, Shen M, Roman HK, Chang PW, Medi S, Greenhow TL. Management of bacteremic urinary tract infections in infants less than 3 months of age. Abstract presented at: Pediatric Academic Societies Annual Meeting; May 5, 2014; Vancouver BC, Canada.

22. Pickering LK, Baker CJ, Kimberlin DW, Long SS. Red Book: 2009 Report of the Committee on Infectious Diseases. 28th ed. Elk Grove Village, IL: American Academy of Pediatrics; 2012.

23. Jones SM, Steele RW. Recurrent group B streptococcal bacteremia. Clin Pediatr (Phila). 2012;51(9):884-887.

24. Fitzgerald A, Mori R, Lakhanpaul M, Tullus K. Antibiotics for treating lower urinary tract infection in children. Cochrane Database Syst Rev. 2012;8:CD006857.

25. Roberts KB. Urinary tract infection: clinical practice guideline for the diagnosis and management of the initial UTI in febrile infants and children 2 to 24 months. Pediatrics. 2011;128(3):595-610.

26. Hodson EM, Willis NS, Craig JC. Antibiotics for acute pyelonephritis in children. Cochrane Database Syst Rev. 2007(4):CD003772.

27. Bocquet N, Sergent Alaoui A, Jais JP, et al. Randomized trial of oral versus sequential IV/oral antibiotic for acute pyelonephritis in children. Pediatrics. 2012;129(2):e269-e275.

28. Bouissou F, Munzer C, Decramer S, et al. Prospective, randomized trial comparing short and long intravenous antibiotic treatment of acute pyelonephritis in children: dimercaptosuccinic acid scintigraphic evaluation at 9 months. Pediatrics. 2008;121(3):e553-e560.

29. Neuhaus TJ, Berger C, Buechner K, et al. Randomised trial of oral versus sequential intravenous/oral cephalosporins in children with pyelonephritis. Eur J Pediatr. 2008;167(9):1037-1047.

30. Magin EC, Garcia-Garcia JJ, Sert SZ, Giralt AG, Cubells CL. Efficacy of short-term intravenous antibiotic in neonates with urinary tract infection. Pediatr Emerg Care. 2007;23(2):83-86.

31. Le Saux N, Howard A, Barrowman NJ, Gaboury I, Sampson M, Moher D. Shorter courses of parenteral antibiotic therapy do not appear to influence response rates for children with acute hematogenous osteomyelitis: a systematic review. BMC Infect Dis. 2002;2:16.

32. Peltola H, Paakkonen M, Kallio P, Kallio MJ. Short- versus long-term antimicrobial treatment for acute hematogenous osteomyelitis of childhood: prospective, randomized trial on 131 culture-positive cases. Pediatr Infect Dis J. 2010;29(12):1123-1128.

33. Zaoutis T, Localio AR, Leckerman K, Saddlemire S, Bertoch D, Keren R. Prolonged intravenous therapy versus early transition to oral 
antimicrobial therapy for acute osteomyelitis in children. Pediatrics. 2009;123(2):636-642.

34. Arnold JC, Cannavino CR, Ross MK, et al. Acute bacterial osteoarticular infections: eight-year analysis of C-reactive protein for oral stepdown therapy. Pediatrics. 2012;130(4):e821-e828.

35. Madrigal VN, Carroll KW, Hexem KR, Faerber JA, Morrison WE, Feudtner C. Parental decision-making preferences in the pediatric intensive care unit. Crit Care Med. 2012;40(10):2876-2882.

36. Merenstein D, Diener-West M, Krist A, Pinneger M, Cooper LA. An assessment of the shared-decision model in parents of children with acute otitis media. Pediatrics. 2005;116(6):1267-1275.

37. Jumani K, Advani S, Reich NG, Gosey L, Milstone AM. Risk factors for peripherally inserted central venous catheter complications in children. JAMA Pediatr. 2013;167(5):429-435.

38. Wang X, Xu Z, Miao CH. Current clinical evidence on the effect of general anesthesia on neurodevelopment in children: an updated systematic review with meta-regression. PLoS One. 2014;9(1):e85760.

39. Langley JM, LeBlanc JC, Wang EE, et al. Nosocomial respiratory syncytial virus infection in Canadian pediatric hospitals: a Pediatric Investigators Collaborative Network on Infections in Canada Study. Pediatrics. 1997;100(6):943-946.

40. Berwick DM, Hackbarth AD. Eliminating waste in US health care. JAMA. 2012;307(14):1513-1516.

41. Schroeder AR, Harris SJ, Newman TB. Safely doing less: a missing component of the patient safety dialogue. Pediatrics. 2011;128(6): e1596-e1597.
42. Committee On Hospital Care and Institute For Patient- and FamilyCentered Care. Patient- and family-centered care and the pediatrician's role. Pediatrics. 2012;129(2):394-404.

43. Porter ME. What is value in health care? N Engl J Med. 2010; 363(26):2477-2481.

44. Cummings EA, Reid GJ, Finley GA, McGrath PJ, Ritchie JA. Prevalence and source of pain in pediatric inpatients. Pain. 1996;68(1):2531.

45. Kanj WW, Gunderson MA, Carrigan RB, Sankar WN. Acute compartment syndrome of the upper extremity in children: diagnosis, management, and outcomes. J Child Orthop. 2013;7(3):225-233.

46. Park CK, Paes BA, Nagel K, Chan AK, Murthy P. Neonatal central venous catheter thrombosis: diagnosis, management and outcome. Blood Coagul Fibrinolysis. 2014;25(2):97-106.

47. Monagle P, Chan AK, Goldenberg NA, et al. Antithrombotic therapy in neonates and children: antithrombotic therapy and prevention of thrombosis, 9th ed: American C ollege of Chest Physicians EvidenceBased Clinical Practice Guidelines. Chest. 2012;141(2 suppl):e737S$801 \mathrm{~S}$.

48. Walsh KE, Landrigan CP, Adams WG, et al. Effect of computer order entry on prevention of serious medication errors in hospitalized children. Pediatrics. 2008;121(3):e421-e427.

49. File TM Jr. Duration and cessation of antimicrobial treatment. J Hosp Med. 2012;7(suppl 1):S22-S33. 